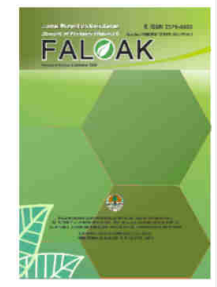

Jurnal Penelitian Kehutanan Faloak (2021) 5(1), 1-15

JURNAL PENELITIAN KEHUTANAN FALOAK

Akreditasi KEMENRISTEKDIKTI: 10/E/KPT/2019

http://ejournal.forda-mof.org/ejournal-litbang/index.php/JPKF

\title{
KEANEKARAGAMAN HERPETOFAUNA DIURNAL DI KAWASAN TAMAN NASIONAL GUNUNG MERBABU (Diversity of Diurnal Herpetofauna in Gunung Merbabu National Park)
}

\author{
Yusuf Prabowo ${ }^{1}$, Muhammad Insan Fathin ${ }^{1}$, A. Iftachil Falach ${ }^{1}$, \\ Ridho Mahesa ${ }^{1}$, dan Rio Christy Handziko ${ }^{1, *}$
}

${ }^{1}$ Laboratorium Zoologi, Jurusan Pendidikan Biologi, FMIPA, UNY.

Jln. Colombo No 1, Karangmalang, Caturtunggal, Depok, Sleman, D.I. Yogyakarta

\begin{abstract}
The diversity of diurnal herpetofauna has an essential role in the ecosystem and is used as an indicator of environmental quality. This study aimed to determine the diversity of herpetofauna species in the southeast slope of the Gunung Merbabu National Park (GMbNP), which is in Ampel Sub-District, Boyolali District, Central Java. The method used in this study was Visual Encounter Survey (VES) in the transect determined purposively around the river, which can become a herpetofauna habitat. Data were collected in the morning session (08.00-14.00 WIB) for six times. This research found 16 species of herpetofauna, as follows: Ahaetulla prasina, Bronchocela jubata, Chalcorana chalconota, Cyrtodactylus marmoratus, Dendrelaphis pictus, Eutropis multifasciata, Gekko gecko, Gonocephalus chamaeleontinus, Leptobrachium hasselti, Megophrys montana, Odorrana hosii, Polypedates leucomystax, Pseudocalotes tympanistriga, Ptyas korros, Python reticulatus, dan Trimeresurus albolabris. The calculation of the level of diversity with the Shannon-Weiner Index showed a value of 2.772 which can be interpreted to have a moderate level of diversity. It implies that the environmental condition of GMbNP is good enough to support herpetofauna species sustainability.
\end{abstract}

Keywords: Amphibi, Reptile, Herpetofauna, Gunung Merbabu National Park,VES

\section{ABSTRAK}

Keanekaragaman herpetofauna mempunyai peranan dalam ekosistem dan digunakan sebagai salah satu parameter kualitas lingkungan. Penelitian ini bertujuan untuk mengetahui keanekaragaman spesies herpetofauna di lereng tenggara kawasan Taman Nasional Gunung Merbabu (TNGMb), yang secara administratif termasuk Kecamatan Ampel, Kabupaten Boyolali, Jawa Tengah. Metode yang digunakan dalam penelitian ini adalah Visual Encounter Survey (VES) pada transek yang ditentukan secara purposive di sekitar sungai dan berpotensi menjadi habitat herpetofauna. Pengambilan data dilakukan pada siang hari (pukul 08.00-14.00 WIB) sebanyak enam kali. Hasil penelitian didapatkan 16 spesies herpetofauna, yaitu: Ahaetulla prasina, Bronchocela jubata, Chalcorana chalconota, Cyrtodactylus marmoratus, Dendrelaphis pictus, Eutropis multifasciata, Gekko gecko, Gonocephalus chamaeleontinus, Leptobrachium hasselti, Megophrys montana, Odorrana hosii, Polypedates leucomystax, Pseudocalotes tympanistriga, Ptyas korros, Python reticulatus, dan Trimeresurus albolabris. Hasil analisis keanekaragaman indeks keanekaragaman Shannon-Weiner menunjukkan nilai 2,772 yang dapat ditafsirkan memiliki tingkat keanekaragaman sedang. Hal ini mengimplikasikan bahwa kondisi lingkungan TNGMb masih cukup baik dalam mendukung kelestarian herpetofauna.

Kata kunci: Amfibi, Reptil, Herpetofauna, Taman Nasional Gunung Merbabu, VES

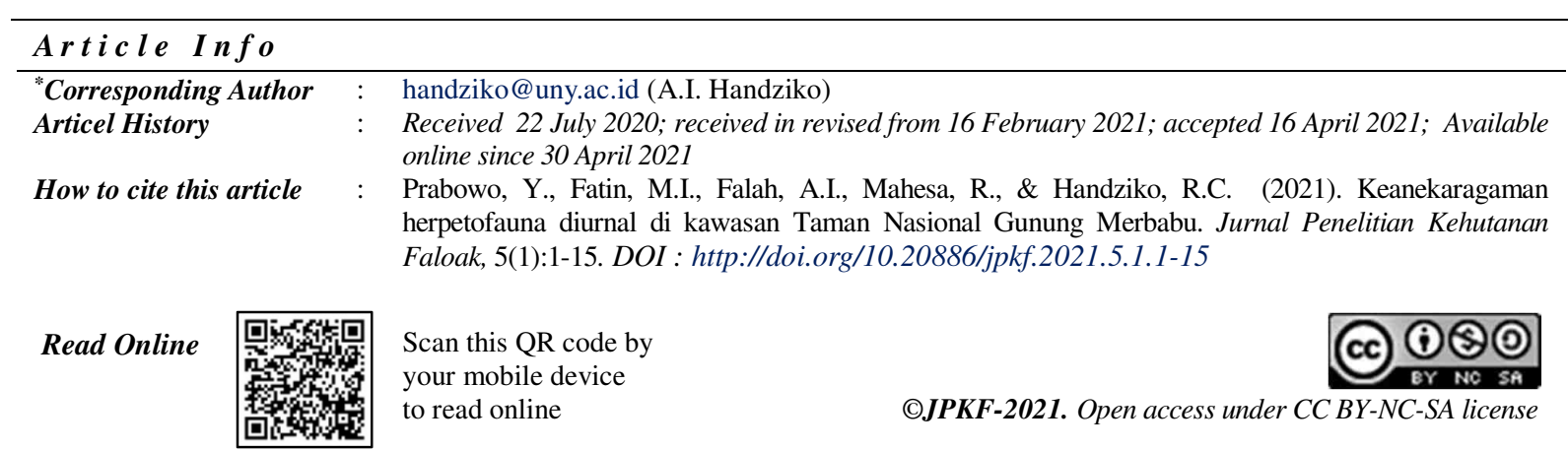




\section{PENDAHULUAN}

Herpetofauna merupakan salah satu potensi keanekaragaman hayati yang belum banyak dikenal oleh masyarakat. Penelitian dan penyebarluasan informasi tentang kelompok satwa ini perlu terus dikembangkan sebagai sarana untuk meningkatkan pengetahuan dan kepedulian masyarakat. Penelitian tentang identifikasi dan inventarisasi herpetofauna memiliki peranan penting dalam studi di bidang biologi, terutama kajian taksonomi, ekologi dan lingkungan. Herpetofauna yang terdiri dari reptil dan amfibi merupakan salah satu potensi keanekaragaman fauna yang jarang diketahui dan kurang dikenal oleh masyarakat. Pemahaman keanekaragaman fauna di suatu kawasan adalah penting, karena masing-masing fauna termasuk herpetofauna memiliki peran dalam menjaga keseimbangan dan keberlangsungan ekosistem kawasan tersebut (Eprilurahman et al., 2009). Peranan herpetofauna di alam antara lain, pengendali hama (jenis-jenis pemakan tikus dan juga serangga) dan sebagai sumber plasma nutfah. Herpetofauna juga merupakan kelompok hewan yang memiliki jenis beragam dan dengan bentuk yang menarik (Irwanto et al., 2019).

Subeno (2018) menyatakan bahwa data keberadaan herpetofauna di wilayah Jawa Tengah, masih sangat minim. Hal ini termasuk di Taman Nasional Gunung Merbabu yang belum memiliki data herpetofauna yang terintegrasi di wilayahnya. Herpetofauna memiliki peranan yang cukup penting karena organisme ini tersebar hidup pada 5 (lima) habitat, yaitu teresterial, aquatic, semiaquatik, arboreal dan fossoreal (Yudha et al., 2015), sehingga memiliki peranan dalam kajian mata rantai ekologis. Keragaman herpetofauna merupakan salah satu parameter keseimbangan dan keberlangsungan ekosistem di suatu kawasan dan kualitas lingkungan di sekitarnya
(Primack, 1998). Adanya data keanekaragaman herpetofauna diharapkan dapat memberikan daya tarik dan nilai tambah tersendiri sebagaimana yang dikemukakan oleh Izza \& Kurniawan (2018) bahwa herpetofauna memiliki nilai potensial sebagai bagian dari ekowisata.

Yudha et al. (2015) menyampaikan bahwa herpetofauna adalah komponen utama dalam sebuah ekosistem yang sering menjadi indikator kualitas lingkungan. Turun, hilang atau berpindahnya populasi suatu jenis organisme pada habitatnya menandakan adanya perubahan kualitas lingkungan pada lokasi tersebut. Herpetofauna yang mempunyai habitat spesifik dapat digunakan sebagai indikator atau peringatan dini terjadinya perubahan lingkungan karena herpetofauna memiliki respon tinggi terhadap perubahan lingkungan. Berdasarkan hal tersebut, maka penelitian tentang keanekaragaman dan persebaran jenis herpetofauna di kawasan Taman Nasional Gunung Merbabu Jawa Tengah terutama di bagian tenggara lereng Gunung Merbabu penting untuk dilakukan. Lokasi penelitian secara administratif masuk dalam wilayah Kecamatan Ampel, Kabupaten Boyolali. Area tenggara lereng Gunung Merbabu ini dipilih sebagai lokasi pengamatan karena adanya sungai yang terus mengalir sepanjang musim yang diduga dapat menjadi tempat berkumpulnya herpetofauna, karena binatang ini biasa ditemui di dekat sumber air. Hasil penelitian ini diharapkan dapat memberikan informasi keanekaragaman dan persebaran individu herpetofauna di kawasan Taman Nasional Gunung Merbabu. Informasi ini juga dapat digunakan sebagai panduan dalam program perlindungan, pengawetan dan pemanfaatan herpetofauna di masa yang akan datang. Manfaat lainnya adalah dapat menjadi sarana edukasi terhadap masyarakat untuk tindakan 
preventif jika bertemu dengan beberapa spesies herpetofauna yang berbisa atau beracun.

\section{METODE PENELITIAN}

Lokasi penelitian adalah pada lereng tenggara Gunung Merbabu, Kecamatan Ampel, Kabupaten Boyolali (Gambar 1). Jenis penelitian adalah penelitian observasi (pengamatan) dengan cara mengamati secara langsung di lapangan dan juga Visual Encounter Survey (VES). Rancangan transek (Heyer et al., 1994) digunakan untuk mengetahui komposisi jenis. Metode VES dipilih karena metode ini adalah metode aktif, sehingga peluang pertemuan dengan organisme herpetofauna menjadi lebih besar (Yudha et al., 2015).
Penggunaan metode transek dipilih karena pertimbangan luas area (Subeno, 2018). Penggunaan metode transek menjadikan proses pengamatan menjadi lebih detail dan terarah.

Penempatan jalur pengamatan (transek) dilakukan secara purposive berdasarkan dua tipe habitat yaitu aquatik dan terestrial (Kusrini, 2008). Transek sepanjang $300 \mathrm{~m}$ ditempatkan di sepanjang Sungai Pantaran sebagai sungai utama, serta beberapa tebing yang bertransformasi menjadi sungai pada musim penghujan. Penempatan transek dilakukan mengikuti keberadaan sungai yang ada di setiap lereng di bagian tenggara Gunung Merbabu. Pada habitat teresterial, jumlah jalur yang dibuat sebanyak enam jalur dan pada tipe habitat akuatik dibuat tiga jalur.

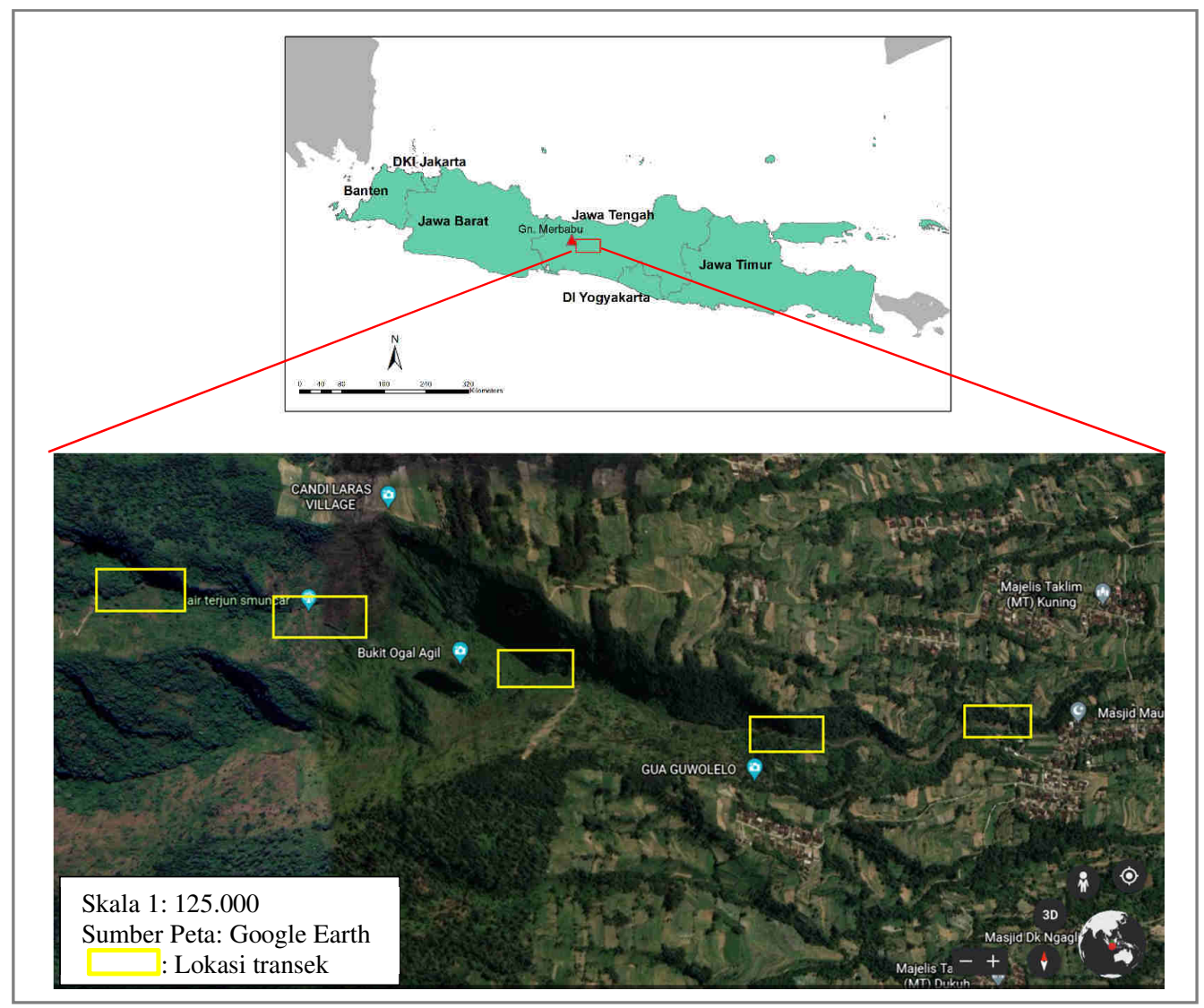

Gambar 1. Lokasi penelitian dan penempatan transek pengamatan (Figure 1. Research location and distribution of transect observation) 
Penentuan lebar jalur bersifat fleksibel mengikuti lebar sungai, dengan arah jalur ke utara. Pengamatan dilakukan di sepanjang badan sungai (aliran air) dan bantaran sungai berjarak 10 meter ( 5 meter ke kanan dan ke kiri badan sungai), dari hilir menuju hulu sungai. Waktu pengamatan dilakukan pada pukul 08.0014.00 WIB, didasarkan pada perilaku herpetofauna yang berjemur guna mendapatkan panas dari lingkungan sehingga kemungkinan teramatinya lebih besar. Jenis data yang dikumpulkan meliputi nama jenis, jumlah, lokasi ditemukan dan aktivitas saat dijumpai. Pengamatan dilaksanakan dalam rentang waktu kurang lebih tiga bulan, yaitu dari pertengahan bulan Maret sampai akhir bulan Mei tahun 2019, setiap tujuh hari sekali dan diulang sebanyak enam kali.

Penelitian hanya fokus dilakukan pada siang hari untuk mengamati spesies diurnal. Analisis data penelitian dilakukan secara deskriptif kuantitatif dan perhitungan indeks keanekaragaman Shanon-Wienner, dengan rumus:

$H^{\prime}=-\sum_{i=1}^{s}\left[\left(\frac{n i}{N}\right) \ln \left(\frac{n i}{N}\right)\right]$

dengan, $H^{\prime}=$ Indeks Keragaman ShannonWiener, $\mathrm{S}=$ Jumlah spesies, $\mathrm{ni}=$ Jumlah individu spesies-i, $\mathrm{N}=$ Total jumlah individu semua spesies.

\section{HASIL DAN PEMBAHASAN}

Hasil penelitian menunjukkan bahwa teridentifikasi 16 individu herpetofauna dari 16 spesies yang berbeda (Tabel 1). Lima spesies merupakan amfibia dari anggota Ordo Anura (katak) dan 11 spesies merupakan reptilia dari Ordo Squamata yang berisi 5 spesies anggota Subordo Serpentes (ular) dan 6 spesies anggota Subordo Lacertilia (kadal). Adapun deskripsi herpetofauna yang ditemukan di lokasi penelitian disajikan pada Tabel 1.

Tabel 1. Macam-macam spesies yang ditemukan di lokasi penelitian Table 1. Various species that found in the research area

\begin{tabular}{|c|c|c|c|c|}
\hline $\begin{array}{c}\text { Kelas } \\
\text { (Class) }\end{array}$ & $\begin{array}{c}\text { Ordo } \\
\text { (Order) }\end{array}$ & $\begin{array}{c}\text { Subordo } \\
\text { (Suborder) }\end{array}$ & $\begin{array}{c}\text { Spesies } \\
\text { (Species) }\end{array}$ & $\begin{array}{l}\text { Kuantitas } \\
\text { (Quantity) }\end{array}$ \\
\hline Reptilia & Squamata & Serpentes & Ahaetulla prasina & 1 \\
\hline \multirow[t]{10}{*}{ (Terestrial) } & & & Dendrelaphis pictus & 1 \\
\hline & & & Python reticulatus & 1 \\
\hline & & & Ptyas korros & 1 \\
\hline & & & Trimeresurus albolabris & 1 \\
\hline & & Lacertilia & Bronchocela jubata & 1 \\
\hline & & & Cyrtodactylus marmoratus & 1 \\
\hline & & & Eutropis multifasciata & 1 \\
\hline & & & Gekko gecko & 1 \\
\hline & & & Gonocephalus chamaeleontinus & 1 \\
\hline & & & Pseudocalotes tympanistriga & 1 \\
\hline Amfibi & Anura & & Chalcorana chalconota & 1 \\
\hline \multirow[t]{4}{*}{ (Akuatik) } & & & Leptobrachium hasselti & 1 \\
\hline & & & Megophrys montana & 1 \\
\hline & & & Odorrana hosii & 1 \\
\hline & & & Polypedates leucomystax & 1 \\
\hline
\end{tabular}




\section{Ahaetulla prasina}

Nama lokal ular ini adalah ular pucuk atau ular gadung pari. Dalam bahasa Jawa disebut gadung yang berarti hijau. Masyarakat juga menyebutnya ular pucuk karena ular ini sering ditemukan di pucuk-pucuk pohon. Ular ini termasuk dalam famili Colubridae dengan ciri umum berwarna hijau pada seluruh tubuhnya, kepalanya berbentuk segitiga dengan ujung mulut yang meruncing, tubuh tipis, kecil, dan panjang, serta pupil mata horizontal. Pada usia dewasa, ular ini dapat mencapai panjang 1,8 m, dengan panjang ekor 0,6 m (Reza et al., 2016). Spesies ini memiliki garis horizontal di dekat sisik ventral yang berwarna putih. Ketika merasakan adanya bahaya, ular ini akan memperlihatkan deretan sisik berwarna hitam, putih, dan biru di bagian lehernya. Ular pucuk tergolong ular berbisa menengah (middle venomous snake) dengan taring di bagian belakang barisan gigi atau Ophistoglypha. Area persebaran ular pucuk mencakup Pulau Sumatra, Jawa, Kalimantan, Bali, dan Nusa Tenggara. Ular pucuk adalah jenis ular arboreal yang memiliki toleransi cukup lebar terhadap jenis tumbuhan dan ketinggian lokasinya. Ular pucuk dapat hidup di dataran rendah maupun dataran tinggi, dan pada berbagai jenis pohon, baik pohon yang tumbuh rendah, bambu, semak-semak, tegakan tinggi bahkan areal pertanian (Rozi \& Samitra, 2020). Ular pucuk adalah ular diurnal dan pada malam hari mereka akan beristirahat di ujung-ujung cabang pohon. Ular pucuk memakan reptil kecil, amfibia, lebih khususnya kadal dan katak pohon (Arius Hady Budiada, 2017).

\section{Dendrelaphis pictus}

Ular ini dikenal dengan nama lain ular tampar, ular tali, atau ular picis. Spesies ini termasuk kelompok Colubridae arboreal yang mudah dijumpai. Ular ini biasa hidup bersama ular pucuk (Ahaetulla prasina). Hal tersebut lazim terjadi karena kedua ular tersebut memiliki mangsa dan preferensi habitat yang sama. Keduanya sama-sama memangsa burung kecil, telur burung, dan hewan lain yang hidup di pohon seperti serangga dan berbagai jenis kadal serta katak pohon. Ular tampar adalah ular tidak berbisa dan tidak berbahaya untuk manusia, meskipun terkadang ular ini cenderung agresif ketika dipegang dan sering menggigit (Harikrishnan et al., 2007). Ciri umum tubuhnya serupa dengan ular pucuk (tipis, kecil dan panjang) namun dengan kepala yang lebih tumpul, mata yang lebih besar dan lidah yang berwarna jingga kemerahan. Bagian dorsal ular ini berwarna perunggu, dengan garis horizontal berwarna hitam di bagian tengah tubuh, dan bagian ventralnya berwarna hijau muda atau kekuningan, garis hitam di setiap sisi kepala melewati mata, melebar atau pecah menjadi bintik-bintik, dipisahkan oleh pita hijau kebiruan di tengkuk, bibir atas berwarna kuning, dan permukaan bawah berwarna kekuningan atau kehijauan. Panjang kepala dan tubuh sekitar $740 \mathrm{~mm}$ dengan panjang ekor $440 \mathrm{~mm}$. Jika terganggu, ular tampar mengembangkan lehernya dan menunjukkan sisik-sisik berwarna hijau kekuningan. Ular ini dapat ditemukan di dataran rendah hingga dataran tinggi dan tidak memiliki preferensi khusus untuk pepohonan yang ditinggali. Ular ini juga termasuk ular diurnal dan dapat ditemukan tidur di pepohonan pada malam hari (Vogel \& van Rooijen, 2008).

\section{Python reticulatus}

Nama lokal ular ini adalah sanca batik, sanca kembang, sowo kembang, ular sawah, piton batik, atau piton berjaring. Python reticulatus adalah ular terpanjang di Indonesia sekaligus di dunia yang termasuk famili Pythonidae dan tersebar di seluruh pulau di Indonesia barat dan peralihan, hingga ke Semenanjung Malaya. Ukuran tubuh sekitar tiga atau empat meter adalah ukuran yang lazim 
ditemukan di pulau Jawa dan merupakan ukuran yang lebih kecil jika dibandingkan dengan jenis yang sama di pulau Sumatra, Kalimantan, atau Sulawesi yang dapat mencapai enam atau tujuh meter. Sanca kembang mudah dikenali dari corak di sisiknya yang berbentuk seperti kain batik atau jaring-jaring. Sanca kembang juga mempunyai indera panas (pit) yang berupa lubang-lubang kecil di bagian mandibula untuk mendeteksi mangsa berdarah panas (Raharjo et al., 2018).

Ular jenis ini belum dilindungi oleh pemerintah Indonesia karena jumlahnya yang masih cukup banyak di alam, bahkan tidak jarang sanca kembang dilaporkan masuk ke perumahan warga atau ditemukan dalam saluran air. Sanca kembang bukan spesies ular berbisa dan tidak bertaring (Aglypha) namun ditakuti oleh manusia karena kemampuannya membunuh mangsa besar dengan cara membelit tubuh korban hingga tidak bisa bernapas. Mangsa sanca kembang amat beragam tergantung pada ukurannya, meskipun tidak ada perbedaan yang signifikan secara morfometri dari pejantan dan betinanya (Nainggolan et al., 2017).

Sanca kembang besar mampu memakan babi hutan, rusa, biawak, buaya, bahkan manusia meskipun manusia bukanlah mangsa normal ular ini, dan kasus kematian manusia akibat dimakan sanca kembang jauh lebih sedikit dibanding kematian ular ini karena manusia. Sanca kembang dapat ditemukan di hutan primer dan sekunder. Ular-ular yang masih muda biasanya arboreal, membelit cabang-cabang pohon dan memangsa hewanhewan pohon, sedangkan sanca dewasa cenderung terestrial dan berburu mangsa dengan cara menyergap. Kematangan seksual biasanya berada pada umur 2-4 tahun. Ular jantan biasanya kawin pada panjang sekitar 2,1-2,7 m, sementara betina kawin pada panjang $3,3 \mathrm{~m}$.
Perkawinan biasanya terjadi antara bulan September-Maret. Ular betina biasanya bertelur dengan jumlah 25-80 yang kemudian dierami selama 80-90 hari, dengan ukuran telur yang besar dan beratnya lebih dari $250 \mathrm{gr}$.

\section{Ptyas korros}

Ptyas korros disebut juga ular koros, ular kayu, ular tikus, atau ular sayur. Jenis ini termasuk dalam famili Colubridae dengan ciri kepala agak meruncing, mata bulat dan besar, tubuhnya berpostur seperti ular pada umumnya dengan bagian dorsal dan sisi tubuh berwarna kecokelatan atau cokelat kekuningan, serta sisik bagian ventral besar-besar dan berwarna kuning. Terkadang dijumpai pula varian warna ular koros dengan sisik dorsal cokelat kekuningan dan garis-garis antarsisik yang jelas berwarna hitam. Lidahnya berwarna hitam. Panjang kepala dan badan ular koros $1.080 \mathrm{~mm}$, dengan panjang ekor $700 \mathrm{~mm}$ (Auliya, 2002; Wicaksono et al., 2020).

Ular koros merupakan ular tidak berbisa (Aglypha) yang umumnya hidup di tanah atau terrestrial. Meskipun begitu ular ini beristirahat di pohon yang rendah atau sedang, terutama ular-ular yang masih remaja. Ular ini dapat bergerak cukup cepat baik di pohon maupun di tanah, dan jika bertemu dengan manusia, ular koros akan memilih melarikan diri dan terhitung jarang menggigit. Penyebarannya terdapat di seluruh pulau Indonesia bagian barat dan Semenanjung Malaya. Makanan utama ular ini berupa tikus dan hewan pengerat lain, namun terkadang juga memakan katak dan anak unggas. Ular koros dapat ditemukan di daerah dataran rendah maupun tinggi, hutan primer maupun sekunder, dan terkadang memasuki areal perumahan manusia untuk berburu binatang pengerat (Dieckmann et al., 2014).

\section{Trimeresurus albolabris}

Nama lokal Trimeresurus albolabris adalah ular bangkai laut, viper hijau ekor merah, 
viper bibir putih, atau ular truno bamban. Ular ini salah satu spesies ular berbisa yang termasuk dalam famili Viperidae. Viper bibir putih dapat dikenali dari tubuhnya yang berwarna hijau, kepala berbentuk segitiga, mulut berwarna putih seperti kapas, dan ujung ekor berwarna merah. Tubuhnya pendek dan agak bongsor dengan panjang maksimal sekitar $60-80 \mathrm{~cm}$, namun yang biasa ditemukan hanya sepanjang 20-30 $\mathrm{cm}$. Viper bibir putih merupakan ular berbisa dengan penyebaran yang amat luas di Indonesia, dapat dijumpai di seluruh pulau Indonesia bagian barat hingga ke zona peralihan (Sulawesi dan Nusa Tenggara) dan Semenanjung Malaya (Devan-Song et al., 2017).

Bisa ular ini bersifat hemotoksik sehingga mampu mengakibatkan pendarahan hebat jika tidak ditolong dengan imobilisasi atau pemberian antivenom. Viper bibir putih memiliki tipe taring Solenoglypha atau taring yang panjang dan dapat dilipat yang terletak di bagian depan mulutnya. Viper bibir putih juga mempunyai pit (lubang pendeteksi inframerah) yang membuatnya mampu berburu di kegelapan dan menangkap mangsa seperti binatang pengerat dan burung. Ular ini adalah ular arboreal yang dapat ditemukan baik di dataran rendah maupun dataran tinggi, dan tidak memiliki preferensi pohon yang khusus (Soogarun et al., 2006).

\section{Bronchocela jubata}

Masyarakat mengenalnya dengan nama bunglon, meskipun nama lokal ini menimbulkan kerancuan. Seringkali juga disebut bunglon hutan, karena kemiripannya dengan kadal ikonik pemakan serangga dari Afrika. Bronchocela jubata termasuk dalam famili Agamidae dan dapat ditemukan di dataran rendah maupun tinggi, dan biasanya ditemukan di pohon berketinggian sedang atau tinggi, meskipun terkadang juga dapat ditemukan di tanah (Eprilurahman et al., 2009). Kadal ini mempunyai ekor yang panjang, duri-duri pada bagian dorsal tubuh, dan kepala berbentuk segitiga dengan semacam bumbungan di atas matanya (Gambar 2). Matanya berukuran besar dan sisik-sisik pada bagian mandibulanya kasar dan berbentuk seperti kantung. Jenis ini memiliki dimorfisme seksual antara individu jantan dan betina.

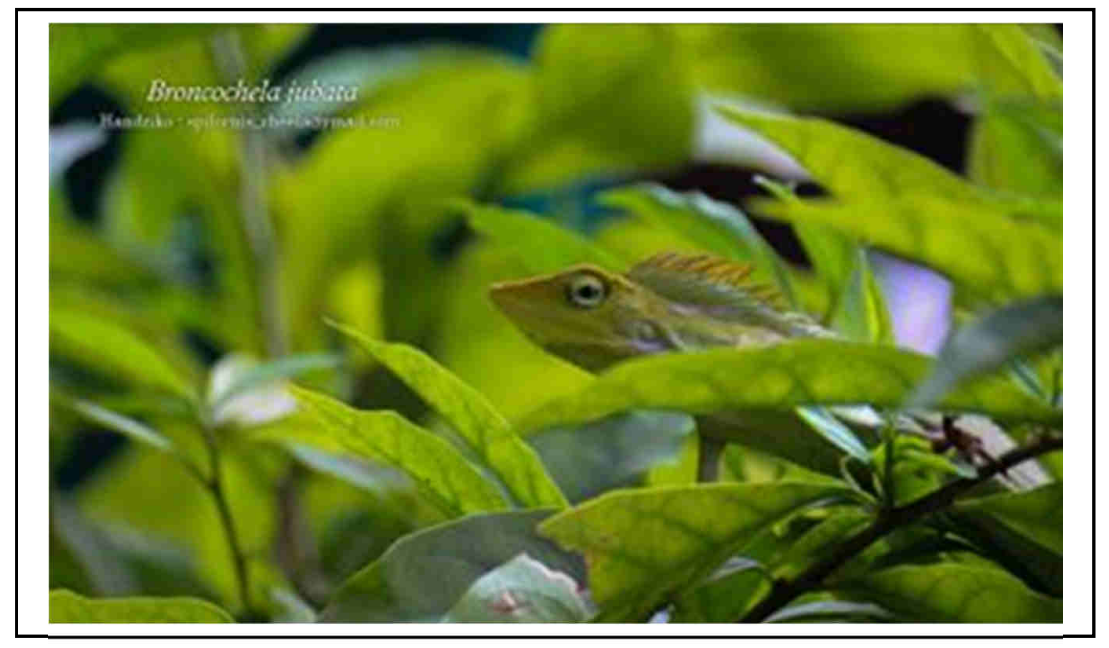

Gambar 2. Bronchocela jubata

Figure 2. Bronchocela jubata 
Bunglon hutan adalah insektivora yang memakan serangga-serangga yang hinggap di pohon menggunakan lidahnya yang panjang dan lengket, meskipun lidahnya tidak lebih panjang jika dibandingkan dengan bunglon sesungguhnya yang berasal dari Afrika. Bunglon hutan yang aktif pada siang hari ini biasanya memilih tetap berdiam diri di tempat tenggerannya jika merasa terancam dan berharap pada kamuflase tubuhnya, meskipun hewan ini juga dapat berlari cepat bila merasa terancam. Penyebarannya luas dari kepulauan Indonesia bagian barat hingga Semenanjung Malaya. Bunglon hutan juga sering ditemukan di pedesaan (Subeno, 2018).

\section{Cyrtodactylus marmoratus}

Jenis Cyrtodactylus marmoratus disebut juga cicak batu, karena sering ditemukan di atas atau di balik batu, terutama di dekat perairan yang mengalir tenang dan dangkal. Meskipun disebut cicak batu dan termasuk dalam famili Gekkonidae, kadal ini tidak memiliki rambutrambut mikroskopik pada bagian telapak kaki dan jarinya (setae) sehingga tidak dapat merayap di dinding atau langit-langit rumah. Sebagai gantinya, cicak nokturnal ini mempunyai cakar melengkung yang mampu mencengkeram batu atau kayu.

Kemampuan adaptasi dan warnanya yang sangat berbeda dengan cicak rumah menyebabkan cicak batu jarang ditemukan di rumah-rumah. Cicak batu memiliki makanan yang sama dengan cicak rumah, yaitu serangga dan invertebrata kecil lain seperti cacing. Cicak batu berukuran sama hingga dua kali lebih besar dibanding cicak rumah, dengan corak yang khas berupa bercak membulat di bagian dorsal tubuh berwarna kecokelatan, kehitaman, atau kehijauan, dan ekor belang-belang keputihan. Ekor ini juga dapat putus bila cicak merasakan bahaya. Cicak batu dapat ditemukan di dataran sedang hingga tinggi, di hutan primer maupun sekunder, dan tersebar di Asia Tenggara, termasuk kepulauan barat Indonesia (Fauzi \& Kurniawan, 2019).

\section{Eutropis multifasciata}

Kadal ini merupakan yang paling umum ditemukan. Eutropis multifasciata atau kadal kebun (mabouya skink dalam bahasa Inggris) tersebar di seluruh Asia Tenggara dan termasuk kadal insektivora yang hidup secara terestrial dan arboreal. Jenis ini ditemukan di permukiman manusia hingga hutan sekunder dan primer, baik yang dekat maupun yang jauh dari sumber air. Spesies kadal yang termasuk dalam famili Scincidae ini memiliki tubuh yang kokoh, penampang badan berupa persegi panjang, bagian dorsal yang datar, empat tungkai yang kecil, kepala agak meruncing, dan mata yang gelap (Subeno, 2018).

Sisik jenis kadal ini bervariasi, namun biasanya berwarna hijau dan cokelat perunggu, dengan variasi warna pada bagian sisi tubuh, yaitu: terkadang berwarna hijau dan terkadang berwarna kuning. Kadal kebun mempunyai celah telinga (porus auditorius) yang terlihat jelas di bagian belakang kepalanya. Kadal kebun umumnya berukuran $15-25 \mathrm{~cm}$ dan dapat merayap cukup cepat untuk mengejar mangsa atau melarikan diri dari predator. Kadal kebun termasuk hewan diurnal yang memiliki preferensi habitat luas karena mangsanya yang beragam, dan dengan mudah mampu beradaptasi dengan berbagai jenis serangga, siput, dan cacing. Di malam hari, mereka tidur di serasah daun atau liang tanah (Ngo et al., 2015).

\section{Gekko gecko}

Tokek rumah atau tokek tokay termasuk dalam famili Gekkonidae yang tersebar luas di Indonesia dan Asia Tenggara. Tokek tokay merupakan salah satu spesies tokek terbesar dengan panjang mencapai $30 \mathrm{~cm}$ atau lebih. Tokek ini dikenali dari ciri morfologisnya yang berupa tubuh berwarna dasar biru muda atau 
biru tua keabu-abuan dengan bintik-bintik merah atau jingga yang tersebar di seluruh tubuh. Bagian dorsalnya memiliki sisik membulat yang tersusun berbaris dalam empat atau lima baris. Matanya yang besar memiliki pupil vertikal dan kadal ini termasuk hewan nokturnal meskipun terkadang masih beraktivitas pada pagi atau senja hari.

Tokek tokay mempunyai setae atau rambut-rambut mikroskopis pada jari mereka sehingga dapat merayap di dinding, pohon, batu, atau langit-langit tanpa terjatuh. Tokek ini juga dapat dengan mudah diketahui keberadaannya melalui suara berisik yang ditimbulkannya pada malam hari. Gekko gecko adalah insektivora yang menangkap mangsa menggunakan lidahnya yang panjang dan lengket. Rahang tokek cukup kuat untuk menggigit eksoskeleton Arthropoda yang keras. Tokek ini sering menunjukkan perilaku agresif ketika berkonfrontasi dengan manusia, dan dalam beberapa kasus diketahui telah menggigit manusia dan tidak melepaskannya hingga beberapa saat. Meskipun demikian, secara keseluruhan tokek ini tidak berbahaya untuk manusia (Rocha et al., 2015)

\section{Gonocephalus chamaeleontinus}

Kadal dari famili Agamidae ini disebut juga sebagai bunglon surai. Perbedaan mendasar antara Gonocephalus chamaeleontinus dan B. jubata adalah tidak adanya tulang berbentuk segitiga pada bagian atas matanya. Selain itu, duri pada bagian dorsal bunglon surai lebih besar dibanding duri bunglon hutan. Bunglon surai mempunyai tubuh berwarna kehijauan yang membuatnya dapat berkamuflase dengan lingkungan sekitarnya. Bunglon surai mempunyai kulit yang lebar di bagian lehernya dan bagian jemari kaki yang panjang berujung cakar melengkung. Bunglon surai tersebar di dataran rendah, sedang, dan tinggi, di hutan sekunder maupun primer, dan terkadang ditemukan di dekat perumahan manusia. Kadal ini mampu beradaptasi dengan berbagai jenis invertebrata kecil sebagai makanannya dan berbagai jenis pohon sebagai tempat tinggalnya mulai dari yang berketinggian sedang hingga tinggi (Yuniar et al., 2014).

\section{Pseudocalotes tympanistriga}

Jenis ini disebut juga dengan kadal agama pohon, merujuk pada famili kadal ini yaitu Agamidae. Pseudocalotes tympanistriga memiliki bangun tubuh yang serupa dengan kadal-kadal arboreal lainnya, namun perbedaannya adalah terdapat lipatan kulit di bagian leher dan rahang bawahnya seperti pada bunglon hutan atau bunglon surai, dan keempat kakinya lebih kecil secara proporsional dibandingkan kebanyakan kadal arboreal. Warna kadal ini bervariasi mulai dari hijau kekuningan berbercak hitam hingga kecokelatan (Yuniar et al., 2014).

Kadal agama pohon merupakan kadal endemik Asia Tenggara dan dapat ditemukan di hutan-hutan primer dan sekunder. Meskipun termasuk hewan arboreal, kadal ini terkadang turun ke tanah untuk berpindah pohon atau mencari makan dan tempat persembunyian lain. Kadal agama pohon merupakan spesies insektivora yang memakan berbagai jenis serangga dan Arthropoda kecil lain yang tinggal di pohon seperti laba-laba (Riyanto, 2009).

\section{Chalcorana chalconota}

Chalcorana chalconota termasuk dalam famili Ranidae dan lebih dikenal dengan nama katak kolam, bangkong kolam, atau kongkang kolam. Jenis ini memiliki ciri khas yaitu hidup secara arboreal maupun semiakuatik. Ciri-ciri jenis ini memiliki ukuran tubuh yang relatif kecil dan langsing, kepala meruncing, serta jarijari kaki panjang dengan ujung membulat untuk menempel pada batu atau kayu. Selaput renangnya penuh hingga ke ujung jari, kecuali pada ujung jari keempat (jari terpanjang). Warnanya bervariasi tergantung musimnya, 
mulai dari kuning (kuning muda hingga kuning tua), hijau dengan bercak kuning atau cokelat, serta ada pula yang hampir sepenuhnya cokelat. Katak ini dapat ditemukan di sepanjang aliran air sungai (Nugraha et al., 2021).

\section{Leptobrachium hasselti}

Nama lain dari jenis Leptobranchium hasselti adalah bangkong serasah atau kodok serasah, dan termasuk dalam famili Megophyridae atau famili katak bertanduk. Bangkong serasah sesungguhnya tidak memiliki organ berbentuk tanduk pada alisnya, namun bagian alisnya tetap menonjol tumpul. Tubuhnya berwarna abu-abu dengan perut bercak-bercak hitam dan cokelat. Kepalanya besar secara proporsional dibandingkan tubuhnya, moncong membulat dan mata berwarna jingga tua atau cokelat gelap. Jari-jari bangkong serasah memiliki selaput yang pendek dan tidak terlalu kentara, berujung melengkung seperti cakar dan tidak memiliki piringan pengisap. Bangkong serasah adalah hewan semiakuatik yang dapat dijumpai di dekat perairan yang tenang seperti sungai berair dangkal dengan bebatuan atau vegetasi di sekelilingnya. Bangkong serasah memiliki persebaran di Asia Tenggara dan dapat ditemui di hutan primer maupun sekunder.

\section{Megophrys Montana}

Megophrys montana lebih popular dengan nama katak bertanduk, hal ini dicerminkan dari sepasang tanduk dari kulit yang berada di atas matanya yang besar. Katak bertanduk termasuk dalam famili Megophyridae dan termasuk katak berukuran besar, berwarna cokelat dengan variasi bintik-bintik hitam yang tersebar. Pada bagian perutnya terkadang dijumpai pola seperti jaring, berwarna hitam, cokelat, putih, atau kemerahan. Bagian tanduk katak bertanduk berwarna sama dengan bagian tubuhnya, dan mata besarnya berwarna cokelat kemerahan atau cokelat gelap. Selain itu, terdapat tonjolan-tonjolan yang tersebar di bagian dorsal dan lateral tubuh. Keempat kaki gempal dan selaput renangnya tidak terlalu kelihatan, serta tidak memiliki piringan pengisap. Katak bertanduk mempunyai mulut yang lebar dan lidah yang panjang serta lengket untuk menangkap mangsa berupa invertebrata kecil. Katak bertanduk umumnya hidup secara terestrial di lantai hutan primer atau sekunder. Penyebarannya adalah sekitar Asia Tenggara.

\section{Odorrana hosii}

Jenis ini populer dengan nama kongkang racun atau katak racun. Amfibi jenis ini berasal dari famili Ranidae dan tersebar di seluruh Asia Tenggara pada hutan sekunder dan primer. Kongkang racun bertubuh kekar dengan ukuran rata-rata individu jantan lebih kecil dari betina. Kulit dorsal $O$. hosii berbintil halus dan rapat, umumnya berwarna hijau terang, hijau lumut, sampai hijau tua, dan ada pula yang kebiruan. Bagian lateral tubuhnya berwarna hijau kekuningan. Sebuah garis gelap, cokelat tembaga hingga kehitaman, dan putus-putus tidak beraturan berada di sisi tubuh mulai dari ujung moncong, pipi, sebelah atas membrana timpani, sebelah bawah lipatan dorsolateral, memanjang hingga ke pinggang.

Kongkang racun merupakan katak semiakuatik dan jarang ditemukan jauh dari sungai. Preferensi habitatnya adalah tepi sungai deras atau sedang yang jernih dan sekelilingnya berbatu. Kehadiran jenis ini menjadi pertanda atau indikator bahwa perairan di lokasi habitatnya masih memiliki air yang baik (Samitra \& Fakhrur Rozi, 2020). Kulit jenis $O$. hosii mengandung racun yang mampu membunuh hewan-hewan kecil dan dapat menyakiti manusia bila sampai termakan. Jika tidak sengaja memegang, cara menghilangkan racunnya cukup dengan mencuci tangan (Oktavina \& Pratiwi, 2015). 


\section{Polypedates leucomystax}

Polypedates leucomystax merupakan jenis katak yang umum ditemukan di pepohonan yang dekat dengan sumber air. Polypedates leucomystax disebut juga katak pohon bergaris atau katak pohon biasa. Katak pohon ini mempunyai kulit berwarna cokelat seperti kulit kayu, dua mata besar berwarna cokelat, dan garis horizontal berwarna hitam pada tubuhnya yang berjumlah 1-2 pasang. Selaput pada kakinya tidak terlalu lebar karena katak ini hidup di pohon, meskipun terkadang juga dapat ditemukan di bebatuan atau vegetasi di sekitar air yang mengalir (Addaha et al., 2015).

Katak pohon bergaris tidak memiliki preferensi terhadap pohon tertentu dan dapat ditemukan di dataran rendah maupun tinggi, hutan primer maupun sekunder. Jenis ini dapat beradaptasi pada berbagai lingkungan selama masih ada vegetasi termasuk rumput-rumputan dan semak. Katak pohon bergaris termasuk famili Rhancophoridae dan merupakan hewan nokturnal pemangsa serangga yang terkadang keluar dari persembunyiannya dengan mengeluarkan bunyi-bunyian yang khas ketika hujan turun (Shahrudin, 2016).

Hasil pengamatan secara keseluruhan menunjukkan bahwa lingkungan lereng tenggara Taman Nasional Gunung Merbabu jalur Ampel merupakan habitat bagi beberapa populasi herpetofauna. Sebaran herpetofauna yang ditemukan pada penelitian ini disajikan pada Gambar 3. Kondisi vegetasi jalur Ampel sangat mendukung keberadaan Amphibia dan Reptilia khususnya ordo Anura, subordo Lacertilian dan Sarpentes. Adanya vegetasi dan bebatuan membentuk mikroklimat yang menunjang habitat amphibi dan reptilian tersebut (Utama et al., 2003). Daerah yang bertajuk rapat serta bervegetasi tinggi umumnya disukai Anura dan Reptilia karena memiliki suhu yang rendah dan kelembaban tinggi serta menjadi tempat bertengger beberapa jenis Sarpentes. Batu-batuan yang terdapat di sungai juga menjadi tempat bersembunyi spesiesspesies yang ditemukan.

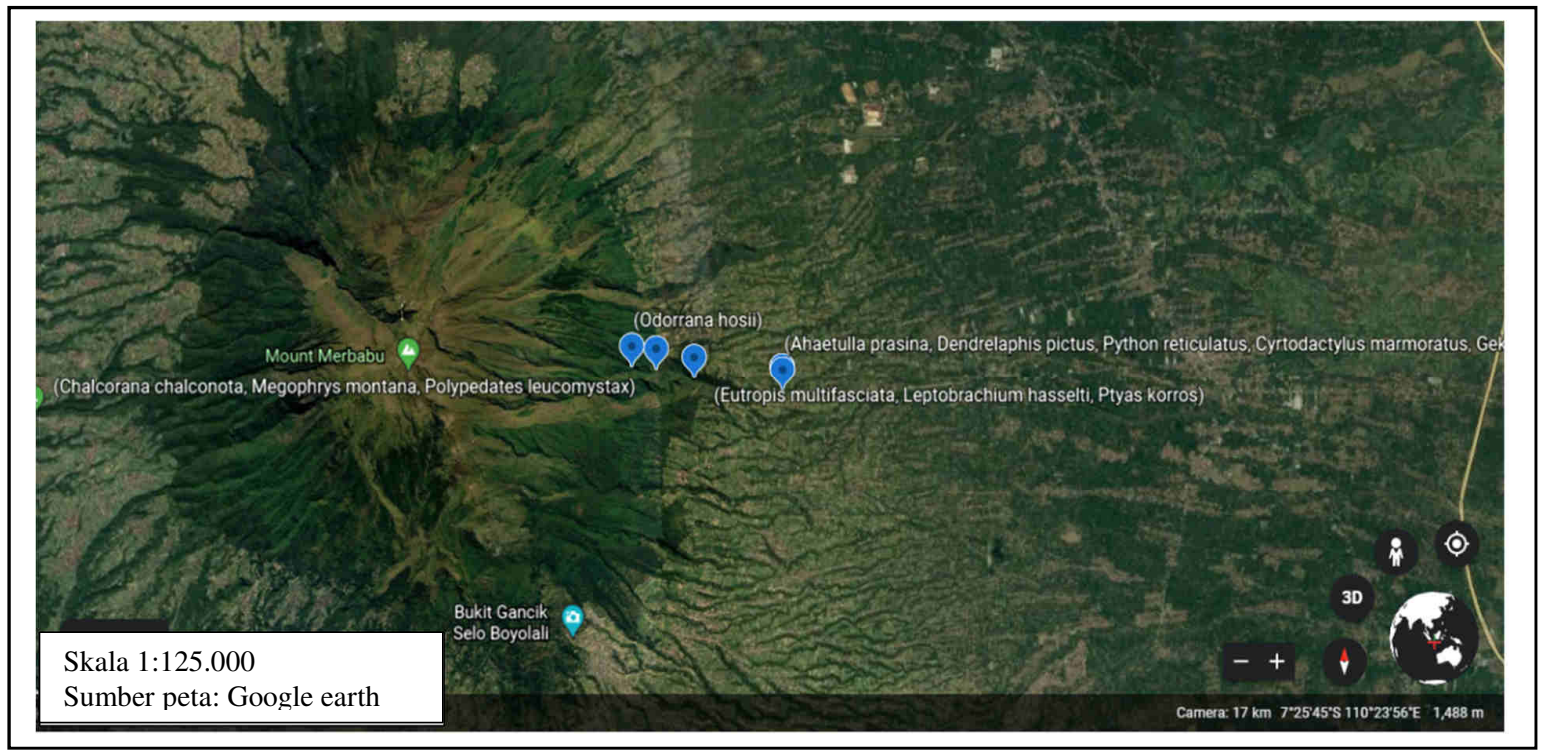

Gambar 3. Sebaran lokasi ditemukannya 11 spesies herpetofauna diurnal di lereng tenggara TN Merbabu

Figure 3. Distribution of locations where 11 species of diurnal herpetofauna were found on the southeast slope of Merbabu National Park 
Semua spesies hanya ditemukan satu individu di sepanjang jalur Ampel. Kondisi medan yang berupa tepi sungai yang curam dan banyaknya celah di antara batuan sungai menjadi rintangan tersendiri sehingga membatasi visual pengamatan terhadap satwa target. Setiap individu yang dijumpai dalam penelitian ini memiliki habitat persebaran di Jawa. Selain itu, juga memiliki persebaran geografi di Sumatra, Papua, dan Melayu (daerah Asia Tenggara), yang memiliki suhu dan kelembaban yang cukup tinggi serta daerah dataran tinggi (Fauzi \& Kurniawan, 2019). Seluruh fauna/individu hanya ditemukan pada musim penghujan, sedangkan pada musim kemarau tidak ditemukan satu spesies pun.

Pada penelitian ini juga dilakukan perhitungan indeks keanekaragaman spesies sebagaimana yang tercatum dalam Tabel 2 . Secara keseluruhan Indeks keanekaragaman
Shannon-Wienner diperoleh nilai 2,77 yang berarti bahwa keanekaragaman spesies herpetofauna yang ditemukan di lereng tenggara Gunung Merbabu jalur Ampel tergolong sedang. Implikasi kategori keanekaragaman herpetofauna yang tergolong sedang ini adalah bahwa Taman Nasional Gunung Merbabu memiliki potensi yang cukup baik dalam kelestarian herpetofauna, namun juga memiliki tingkat risiko yang tinggi. Jika pengelolaan kawasan tidak cukup baik, maka akan berimplikasi pada berkurangnya habitat alami herpetofauna, dan bukan tidak mungkin indeks keanekaragaman herpetofauna akan terus menurun. Edukasi pada masyarakat masih diperlukan karena masih cukup banyak masyarakat yang menghubungkan kehadiran ular adalah sebuah kesialan sehingga akan mengancam keberadaan herpetofauna khususnya jenis ular.

Tabel 2. Hasil perhitungan indeks Shannon-Wiener

Table 2. The result of Shannon-Wiener index calculation

\begin{tabular}{|c|c|c|c|c|}
\hline $\begin{array}{l}\text { Kelas } \\
\text { (Class) }\end{array}$ & $\begin{array}{c}\text { Ordo } \\
(\text { Order })\end{array}$ & $\begin{array}{c}\text { Subordo } \\
\text { (Suborder) }\end{array}$ & $\begin{array}{c}\text { Spesies } \\
(\text { Species }) \\
\end{array}$ & $\begin{array}{l}\text { Indeks Shannon } \\
\text { (Shannon Index) }\end{array}$ \\
\hline \multirow[t]{11}{*}{ Reptilia } & Squamata & Serpentes & Ahaetulla prasina & 0.173 \\
\hline & & & Dendrelaphis pictus & 0.173 \\
\hline & & & Python reticulatus & 0.173 \\
\hline & & & Ptyas korros & 0.173 \\
\hline & & & Trimeresurus albolabris & 0.173 \\
\hline & & Lacertilia & Bronchocela jubata & 0.173 \\
\hline & & & Cyrtodactylus marmoratus & 0.173 \\
\hline & & & Eutropis multifasciata & 0.173 \\
\hline & & & Gekko gecko & 0.173 \\
\hline & & & Gonocephalus chamaeleontinus & 0.173 \\
\hline & & & Pseudocalotes tympanistriga & 0.173 \\
\hline \multirow[t]{5}{*}{ Amfibi } & Anura & & Chalcorana chalconota & 0.173 \\
\hline & & & Leptobrachium hasselti & 0.173 \\
\hline & & & Megophrys montana & 0.173 \\
\hline & & & Odorrana hosii & 0.173 \\
\hline & & & Polypedates leucomystax & 0.173 \\
\hline
\end{tabular}




\section{KESIMPULAN}

Hasil penelitian menunjukan terdapat 16 spesies herpetofauna di lereng tenggara Gunung Merbabu, terdiri dari 11 spesies reptilia dan 5 spesies amfibi. Masing-masing spesies dijumpai satu individu dan pola penyebarannya menyebar di sepanjang aliran sungai. Indeks keanekaragaman Shannon-Wienner menunjukkan nilai 2,772 yang berarti tingkat keanekaragamannya pada tingkat sedang. Hal ini mengindikasikan kondisi lingkungan di TNGM masih cukup baik dalam mendukung kelestarian spesies herpetofauna.

Penelitian ini hanya dilakukan pada siang hari, sehingga perlu adanya penelitian lanjutan mengenai keanekaragaman spesies herpetofauna di lereng tenggara Gunung Merbabu, terutama untuk pengamatan herpetofauna nocturnal agar keberadaannya dapat terpantau dengan baik.

\section{UCAPAN TERIMA KASIH}

Penulis mengucapkan terima kasih kepada Balai Taman Nasional Gunung Merbabu yang telah memberikan izin dan memfasilitasi pelaksanaan penelitian. Penulis juga mengucapkan terimakasih kepada Bapak Tugimin yang mendampingi saat pengambilan data di lapangan.

\section{DAFTAR PUSTAKA}

Addaha, H., Hon Tjong, D., \& Novarino, W. (2015). Variasi morfologi katak pohon bergaris Polypedates leucomystax Gravenhorst, 1829 (Anura; Rhacophoridae) di Sumatera Barat. Natural Sciences: Jurnal of Science and Technology, 4(3), 348-354. https://doi.org/10.22487/25411969.2015. v4.i3.5140

Arius Hady Budiada, I. G. M. (2017). Keanekaragaman spesies ular di Desa Pering, Kecamatan Blahbatuh, Kabupaten Gianyar,
Bali. Jurnal Biologi Udayana, 21(1), 7. https://doi.org/10.24843/JBIOUNUD.2017. vol21.i01.p02

Auliya, M. (2002). Rediscovery of the Indochinese Rat Snake Ptyas korros (Schlegel, 1837) (Serpentes: Colubridae) in Borneo. Raffles Bulletin of Zoology, 50(1), 197-198.

Devan-Song, A., Martelli, P., \& Karraker, N. E. (2017). Reproductive biology and natural history of the White-lipped Pit Viper (Trimeresurus albolabris Gray, 1842) in Hong Kong. Herpetological Conservation and Biology, 12(1), 56-67.

Dieckmann, S., Norval, G., \& Mao, J. J. (2014). A description of a clutch of the IndoChinese Rat Snake Ptyas korros (Schlegel, 1837), with notes on an instance of twinning. Herpetology Notes, 7(December 2015), 397-399.

Eprilurahman, R., Hilmy, M. F., \& Qurniawan, T. F. (2009). Studi keanekaragaman Reptil dan Amfibi di Kawasan Ekowisata Linggo Asri, Pekalongan, Provinsi Jawa Tengah. Berkala Penelitian Hayati, 15(1), 93-97.

https://doi.org/10.23869/bphjbr.15.1.2009 15

Fauzi, M. A., \& Kurniawan, N. (2019). Classification of Cyrtodactylus marmoratus species complex based on the molecular approach. Journal of Physics: Conference Series, 1146(1), 012040. https://doi.org/10.1088/1742$6596 / 1146 / 1 / 012040$

Harikrishnan, S., Deepak, V., \& Vasudevan, K. (2007). Report of painted bronze-back tree snake Dendrelaphis pictus Gmelin, 1789 from Anamalais, Western Ghats, India. Zoos' Print Journal, 22(12), 2929. https://doi.org/10.11609/jott.zpj.1841.292 
9

Heyer, W. R., Donnelly, M. A., McDiarmid, R. W., Hayek, L. C., \& Foster, M. S. (1994). Measuring and monitoring Biological Diversity: Standard methods for Amphibians. Smithsonian Institution Press. Washington DC: Smithsonian Institution Press.

Irwanto, R., Lingga, R., Pratama, R., \& Ifafah, S. A. (2019). Identifikasi jenis-jenis Herpetofauna di Taman Wisata Alam Gunung Permisan, Bangka Selatan, Provinsi Kepulauan Bangka Belitung. PENDIPA Journal of Science Education, 3(2), 106113.

https://doi.org/10.33369/pendipa.v3i2.7707

Izza, Q., \& Kurniawan, N. (2014). Eksplorasi jenis-jenis Amfibi di Kawasan OWA Cangar dan Air Terjun Watu Ondo Gunung Welirang, TAHURA R.Soejo. Jurnal Biotropika, 2(2), 103-108.

Kusrini, M. D. (2008). Keanekaragaman Amfibi pada berbagai tipe habitat (Fitriyanti, ed.). Bogor: IPB Press.

Nainggolan, K., Kusrini, M. D., \& Kartono, A. P. (2017). Karakteristik ular sanca batik (Python reticulatus) yang dipanen di Sumatera Utara. Jurnal Penelitian Hutan Dan Konservasi Alam, 14(1), 45-55.

Ngo, C. D., Ngo, B. V., Hoang, T. T., Nguyen, T. T. T., \& Dang, H. P. (2015). Feeding ecology of the common sun skink, Eutropis multifasciata (Reptilia: Squamata: Scincidae), in the plains of central Vietnam. Journal of Natural History, 49(39-40), 2417-2436. https://doi.org/10.1080/00222933.2015.1 021876

Nugraha, F. A. D., Amardi, Y., Kentino, M., Agusdi,
K., \& Rinaldo, R. (2021). Inventarisasi awal jenis Amfibi di kawasan Malibo Anai ( Provinsi Sumatera Barat ) dengan keterangan habitatnya. Quagga: Jurnal Pendidikan Dan Biologi, 1(February), 82-87. https://doi.org/10.25134/quagga.v13i1.3738

Oktavina, M. A., \& Pratiwi, R. (2015). Pola protein sekret kelenjar parotoid tiga spesies Kodok dan sekret kelenjar kulit Katak Kongkang Racun (Odorrana hosii Boulenger, 1891 ). SDS-PAGE. 199-204.

Primack, R. S. (1998). A Primer of consevation biologi. Yayasan Obor Indonesia. Jakarta: Yayasan Obor Indonesia.

Raharjo, S., Hartati, S., Indarjulianto, S., Widayanti, R., \& Nururrozi, A. (2018). Kajian filogenetik ular sanca batik (Malayopython reticulatus) lokalitas Jawa berdasar sekuen gen sitokrom B. Jurnal Veteriner, $19(2), \quad 284$. https://doi.org/10.19087/jveteriner.2018.1 9.2.284

Reza, F., Tjong, D. H., \& Novarianto, W. (2016). Description of the species of snakes on a university campus field andalas limau manih padang. BioConcetta, 2(2), 13-27.

Riyanto, A. (2009). Studi Pendahuluan mengenai pakan Londok Moncong Pseudocalotes tympanistriga (Squamata: Agamidae) di Sisi Barat Gunung Ciremai. Jurnal Biologi Indonesia 5(3), 377-380.

Rocha, J. C., Piva, A., Batista, J., \& Machado, D. C. (2015). Occurrence of the Tokay Gecko Gekko gecko (Linnaeus 1758) (Squamata, Gekkonidae), an exotic species in southern Brazil. Herpetology Notes, 8(January), 8-10.

Rozi, Z. F., \& Samitra, D. (2020). Amphibians diversity in Sulap Hill and Watervang Dam, 
Lubuklinggau. Jurnal Biodjati, 5(1), 153163.

https://doi.org/10.15575/biodjati.v5i1.5340

Samitra, D., \& Fakhrur Rozi, Z. (2020). Short Communication: The Herpetofauna around human settlements in Lubuklinggau City, South Sumatra, Indonesia: Composition and diversity. Biodiversitas Journal of Biological Diversity, 21(4), 1432-1437. https://doi.org/10.13057/biodiv/d210422

Shahrudin, S. (2016). Defensive strategies of Polypedates leucomystax (Gravenhorst, 1829) (Anura: Rhacophoridae) from peninsular Malaysia. Herpetology Notes, 9(August), 163-165.

Soogarun, S., Choewbamrungkiat, M., Wiwanitkit, V., Suwansaksri, J., Nopanitaya, W., Pradniwat, P., ... Chanprasert, S. (2006). Study on the effect of Green Pit Viper venom (Trimeresurus albolabris) on platelet morphology by flow cytometry. Online Journal of Health and Allied Sciences, 5(3).

Subeno, S. (2018). Distribusi dan keanekaragaman Herpetofauna di Hulu Sungai Gunung Sindoro, Jawa Tengah.
Jurnal Ilmu Kehutanan, 12(1), 40. https://doi.org/10.22146/jik.34108

Vogel, G., \& van Rooijen, J. (2008). Contributions to a review of the A (Gmelin, 1789) complex - 2. the eastern forms (Serpentes: Colubridae). Herpetozoa, 21(1/2), 3-29.

Wicaksono, A., Madang, K., \& Dayat, E. (2020). Identifikasi jenis-jenis ular di Desa Muktijaya Kecamatan Muara Telang Kabupaten Banyuasin dan Sumbangsihnya Pada Pembelajaran Biologi Sma/Ma. Bioilmi, 6(1), 1-10. https://doi.org/10.19109/bioilmi.v6i1

Yudha, D. S., Yonathan, Y., Eprilurahman, R., Indriawan, S., \& Cahyaningrum, E. (2015). Keanekaragaman dan kemerataan spesies anggota Ordo Anura di Lereng Selatan Gunung Merapi Tahun 2012. Biosfera, $\quad 32(1), \quad 1$. https://doi.org/10.20884/1.mib.2015.32.1. 289

Yuniar, D., Isfaeni, H., Sukandar, P., \& Noer, M. I. (2014). Jenis-jenis Reptilia di PPKA Bodogol, Taman Nasional Gunung Gede Pangrango. Bioma, 10(1), 45. https://doi.org/10.21009/bioma10(1).6 